Journal of

Applied

Crystallography

ISSN 0021-8898

Editor: Anke R. Kaysser-Pyzalla

\title{
Quantitative X-ray diffraction phase analysis of poorly ordered nontronite clay in nickel laterites
}

\section{Xiaodong Wang, Jian Li, Robert D. Hart, Arie van Riessen and Robbie McDonald}

J. Appl. Cryst. (2011). 44, 902-910

Copyright (C) International Union of Crystallography

Author(s) of this paper may load this reprint on their own web site or institutional repository provided that this cover page is retained. Republication of this article or its storage in electronic databases other than as specified above is not permitted without prior permission in writing from the IUCr.

For further information see http://journals.iucr.org/services/authorrights.html

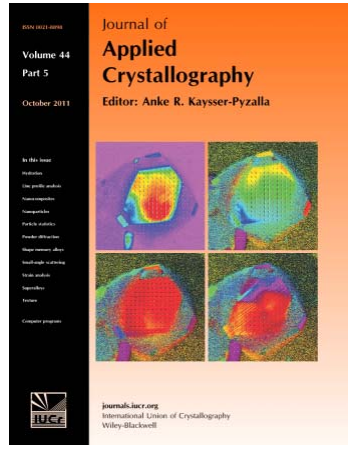

Journal of Applied Crystallography covers a wide range of crystallographic topics from the viewpoints of both techniques and theory. The journal presents papers on the application of crystallographic techniques and on the related apparatus and computer software. For many years, the Journal of Applied Crystallography has been the main vehicle for the publication of small-angle scattering papers and powder diffraction techniques. The journal is the primary place where crystallographic computer program information is published.

Crystallography Journals Online is available from journals.iucr.org 
Journal of

Applied

Crystallography

ISSN 0021-8898

Received 13 April 2011

Accepted 11 July 2011

\section{Quantitative X-ray diffraction phase analysis of poorly ordered nontronite clay in nickel laterites}

\author{
Xiaodong Wang, ${ }^{\mathrm{a} *}$ Jian Li, ${ }^{\mathrm{b}}$ Robert D. Hart, ${ }^{\mathrm{a}}$ Arie van Riessen ${ }^{\mathrm{a}}$ and Robbie \\ McDonald ${ }^{\mathbf{b}}$
}

a Department of Imaging and Applied Physics, Curtin University, GPO Box U1987, Perth, WA 6845, Australia, and ${ }^{\mathbf{b}}$ Division of Process Science and Engineering, CSIRO, PO Box 7229, Karawara, WA 6152, Australia. Correspondence e-mail: xiaodong.wang1@postgrad.curtin.edu.au

\begin{abstract}
Studies of the extraction of nickel from low-grade laterite ores require a much better quantitative understanding of the poorly ordered mineral phases present, including turbostratically disordered nontronite. Whole pattern refinements with nontronite X-ray diffraction data from a Western Australian nickel deposit (Bulong) using a nontronite lattice model (Pawley phase) with two space groups $(P 3$ and $C 2 / m)$ and a peaks phase group model were performed to improve the accuracy of quantitative X-ray diffraction of nickel laterite ore samples. Modifications were applied when building the new models to accommodate asymmetric peak shape and anisotropic peak broadening due to the turbostratic disorder. Spherical harmonics were used as convolution factors to represent anisotropic crystal size and strain and asymmetric peak shape when using the lattice model. A peaks phase group model was also developed to fit the anisotropic peak broadening in the nontronite pattern. The quantitative results of the new Pawley phase and peaks phase group models were compared and verified with synthetic mixtures of nontronite, quartz and goethite simulating various West Australian laterite ore compositions. The models developed in this paper demonstrate adequate accuracy for quantification of nontronite in the synthesized reference materials and should be generally applicable to quantitative phase analysis of nontronite in nickel laterite ore samples.
\end{abstract}

\section{Introduction}

Vast resources of nickel are distributed in low-grade laterite ores in Western Australia. The nickel is commonly present in the goethite-rich part of the profile but is also present in the iron-rich smectite clay - nontronite (McDonald \& Whittington, 2008; Gaudin et al., 2005). Studies of the high-pressure acid leaching and heap leaching behaviours of these ores are hindered by inadequate quantification of the mineral phases present (Elliot et al., 2009; Scarlett et al., 2008). The mineral phases are not readily quantifiable using the usual Rietveld approach because the phases are often poorly ordered and different from their standard crystal structure. Nontronite is frequently the most poorly characterized phase in these samples.

The most distinctive feature of the nontronite powder X-ray diffraction pattern is the 001 basal reflection, which has been found to have $d$ values varying from 9.7 to $15 \AA$ owing to increases in the $c$-axis length through hydration of the interlayer cations (Ufer et al., 2008; Bayliss, 1989; Besson et al., 1983; Eggleton, 1977; Keeling et al., 2000; Tsipursky \& Drits, 1984; Dekov et al., 2007). As a member of the swelling smectite family, nontronite can vary in its chemical composition, with cation substitutions and assorted hydration states causing variations in its crystal structure. Asymmetric non-basal peaks are often present in its X-ray diffraction (XRD) pattern as a result of turbostratic disorder, which commonly occurs in smectite (Moore \& Reynolds, 1997, p. 340). A typical formula for nontronite is $\mathrm{Na}_{x}{ }^{\mathrm{VI}}(\mathrm{Fe}, \mathrm{Al}, \mathrm{Mg})_{2}{ }^{\mathrm{IV}}(\mathrm{Si}, \mathrm{Al})_{4} \mathrm{O}_{10}(\mathrm{OH})_{2} \cdot n \mathrm{H}_{2} \mathrm{O}$, where $x$ can vary from 0.1 to 0.3 and superscripts VI and IV represent octahedral and tetrahedral sites (Whittington et al., 2003; Keeling et al., 2000; Scarlett et al., 2008). For hydrated nontronite there is no crystallographic information file (CIF) available in either the Inorganic Crystal Structure Database or the American Mineralogist Crystal Structure Database. Without a known structure it is difficult to quantify a phase by the well developed Rietveld method (Bish \& Howard, 1988; Hill \& Howard, 1987; O'Connor \& Raven, 1988).

Bruker DIFFRAC $C^{\text {plus }}$ TOPAS (Bruker AXS Inc., Madison, Wisconsin, USA) software provides three levels of refinement of 'fit objects': (1) structural models containing space group, lattice dimensions, and atomic species and their positions in the unit cell; (2) lattice models (Pawley phase or Le Bail phase) specifying space group, lattice dimensions and empirical structure factors; and (3) peaks phase models, which include a group of related peak positions and peak areas. Fewer crystallographic relationships are used by the latter than the former. The structural model is the only approach suitable for conventional Rietveld quantitative phase analysis 
(QPA); however, it fails when a phase structure is not available. Scarlett \& Madsen (2006) demonstrated a successful quantification method of corundum and nontronite from Port Lincoln, South Australia, using a lattice model for phases with partial or no known crystal structure (PONKCS method). Scarlett et al. (2008) have since used this nontronite peaks phase model to study pressure acid leaching of ores. However, currently neither model is able to fit patterns with asymmetric peak shapes or anisotropic peak broadening, unless peak shape modifiers are applied. The present paper demonstrates peak shape modifiers that allow both models to fit patterns containing anisotropic peak broadening and asymmetric peak shape.

In order to obtain a better model to quantify nontronite in Western Australian nickel laterite ores, this study developed nontronite Pawley phase models for laterite ores from the Bulong mine in Western Australia (Taylor, 2007). Spherical harmonics (SH) were used as convolution factors to represent the anisotropic crystal size and strain and asymmetric peak shape in Pawley phase models. The SH are two-dimensional anisotropic function series of directions in spherical coordinates, or of $h k l$ indices in lattice space, and were first introduced into XRD analysis by Järvinen (1993) to model the particle direction distribution (preferred orientation) of powder samples. A peaks phase group model was also developed to fit the anisotropic peak broadening of the nontronite pattern. Validations of the models were performed using synthetic mixtures simulating the typical compositions for Western Australian nickel laterite ores. The application of a specific refinement strategy is required when applying peak shape modifiers to the Pawley phase model in Rietveld quantification. A flow chart for the development of the modified models is presented to demonstrate the routes used to establish QPA models based on different crystallographic information.

\section{Materials and methods}

\subsection{Sample preparation and characterization}

The nontronite used in this study was obtained from a nontronite-rich sample using particle-size separation. The powder sample was thoroughly washed with deionized water until the particles were well dispersed and then allowed to settle in a glass cylinder for $1 \mathrm{~h}$. This settling time was calculated using Stokes's law based on complete settling of $10 \mu \mathrm{m}$ (equivalent spherical diameter) of kaolinite $\left(2.62 \mathrm{~g} \mathrm{~cm}^{-3}\right)$ and $30 \mu \mathrm{m}$ of quartz $\left(2.65 \mathrm{~g} \mathrm{~cm}^{-3}\right)$, as these were the main impurities found in the original nontronite sample [confirmed by XRD and transmission electron microscopy (TEM)]. The top $25 \mathrm{~cm}$ of the remaining dispersed fraction was collected and this procedure was repeated several times to obtain sufficient sample for subsequent experiments. The separated suspension was oven dried at $343 \mathrm{~K}$, and the dried sample formed a selfsupporting green-coloured nontronite film. After this enrichment, the sample was confirmed by XRD phase identification (details below) as predominantly nontronite with only trace amounts of quartz and kaolinite.
The enriched sample was micronized in ethanol using a McCrone micronizer, again oven dried at $343 \mathrm{~K}$, and side loaded into an XRD holder to minimize preferred orientation effects (Moore \& Reynolds, 1997, p. 222). The XRD pattern of the enriched nontronite sample was obtained using a Bruker D8 Advance diffractometer with $\mathrm{Cu} K \alpha$ radiation, a LynxEye detector with tight energy discrimination limits to reduce iron fluorescence effects and a knife-edge collimator to reduce air scattering of the primary beam at low angles. The $2 \theta$ angular range of the linear position-sensitive detector (LynxEye) was $3^{\circ}$ at $250 \mathrm{~mm}$ radius. The data were collected from 3 to $100^{\circ} 2 \theta$ with step size $0.02^{\circ} 2 \theta$ at $1.5 \mathrm{~s} \mathrm{step}^{-1}$, using a $0.3^{\circ}$ fixed divergence slit and $2.5^{\circ}$ primary and secondary Soller slits. These instrument parameters were used in the fundamental parameter approach to determine instrumental profiles (Cheary \& Coelho, 1992).

The chemical composition of the Bulong nontronite was determined by inductively coupled plasma emission spectrometry (ICP-OES) after fusion with Sigma Chemicals 12:22 lithium borate flux and dissolution in water.

Calcium fluorite $\left(\mathrm{CaF}_{2}\right.$, Sigma-Aldrich, assay > 99.5\%) powder was used as an internal standard. Five standard mixtures of enriched nontronite and $\mathrm{CaF}_{2}$ (weight ratios 1:9, 3:7, 5:5, 7:3, 9:1) were mixed in ethanol using a McCrone micronizer, oven dried at $343 \mathrm{~K}$, and gently ground in an agate mortar and pestle before side loading into a plastic XRD holder. The scanning conditions were the same as those used for the enriched nontronite sample.

Six independent mixtures of quartz, goethite and the enriched Bulong nontronite simulating various common phase compositions of Western Australian nickel laterite (Elias et al., 1981; Landers et al., 2009; Singh \& Gilkes, 1992) were also mixed using a McCrone micronizer. The detailed weight ratios are shown in Table 1. The quartz (Cook Industrial Minerals Pty Ltd) and goethite (Synergy Pigments Australia Pty Ltd) were verified to be pure phases and their lattice parameters were predetermined with $2 \theta$ correction (zero error and sample displacement error) by an internal standard method (McCusker et al., 1999).

\subsection{The modified model for the PONKCS method}

Bruker DIFFRAC ${ }^{\text {plus }}$ EVA (version 15) software with the International Centre for Diffraction Data (http:// www.icdd.com/) PDF-4 2009 database were used for phase identification. Bruker DIFFRAC $C^{\text {plus }}$ TOPAS (version 4.2) software was used as the exclusive tool for the whole powder pattern fitting (WPPF), iterative least-squares indexing (LSI indexing), lattice parameter search (LP search), whole powder pattern decomposition (WPPD) and Rietveld quantitative analysis. A flow chart describing the processes of applying the modified PONKCS method to nontronite is shown in Fig. 1. The two major stages, indicated as 'Build Pawley phase model' and 'Calibrate $Z M V$ factor', are detailed below (' $Z M$ ' refers to the mass and ' $V$ ' refers to the volume of the unit cell). The route for using the peak phase group method for nontronite phase quantification is also demonstrated. 
Table 1

Quantitative results of six synthetic mixtures of goethite (Goe), quartz (Qrt) and nontronite (Nont).

Figures in brackets represent the $1 \sigma$ uncertainty on the last decimal place.

\begin{tabular}{|c|c|c|c|c|c|c|c|c|c|c|c|}
\hline \multicolumn{3}{|c|}{ Weighed wt\% } & \multicolumn{3}{|c|}{$\begin{array}{l}\text { SH-assisted } P 3 \text { Pawley phase model } \\
\text { calculated } \mathrm{wt} \%\end{array}$} & \multicolumn{3}{|c|}{$\begin{array}{l}\text { SH-assisted } C 2 / m \text { Pawley phase model } \\
\text { calculated } \mathrm{wt} \%\end{array}$} & \multicolumn{3}{|c|}{$\begin{array}{l}\text { Peaks phase group } \\
\text { calculated wt } \%\end{array}$} \\
\hline Nont & Goe & Qrt & Nont & Goe & Qrt & Nont & Goe & Qrt & Nont & Goe & Qrt \\
\hline 10.03 & 70.13 & 19.84 & $12.6(6)$ & $67.0(5)$ & $20.5(2)$ & $12.5(1)$ & $67.4(2)$ & $20.1(1)$ & $12.6(5)$ & $66.8(2)$ & 20.5 (1) \\
\hline 15.07 & 55.02 & 29.91 & $18.1(8)$ & $50.0(5)$ & 31.9 (3) & $17.6(4)$ & $50.4(2)$ & $32.0(2)$ & $16.1(7)$ & $51.0(1)$ & 32.8 (1) \\
\hline 19.96 & 39.96 & 40.08 & $20.3(5)$ & 37.7 (3) & 42.1 (3) & $21.5(8)$ & 37.2 (4) & $41.3(4)$ & $20.1(8)$ & $37.6(1)$ & $42.4(1)$ \\
\hline 30.02 & 20.08 & 49.90 & $26.6(4)$ & 19.1 (1) & $54.3(3)$ & $26.8(3)$ & $19.3(1)$ & $53.9(2)$ & $25(1)$ & 19.7 (1) & $55.6(2)$ \\
\hline 34.97 & 50.01 & 15.02 & $36.3(7)$ & $47.2(5)$ & $16.5(2)$ & $37.3(5)$ & $46.6(4)$ & 16.1 (1) & 35 (1) & $48.4(2)$ & $17.0(1)$ \\
\hline 49.97 & 24.92 & 25.11 & $47.2(7)$ & $24.3(4)$ & $28.6(4)$ & $50.8(5)$ & $22.6(2)$ & $26.6(3)$ & 43 (1) & $26.3(2)$ & $31.2(2)$ \\
\hline
\end{tabular}

2.2.1. Building the lattice models. Two routes for building the Pawley phase model are demonstrated in the first stage. As indicated in the right-hand route in Fig. 1, one Pawley phase model was developed using a hexagonal $P 3$ space group according to PDF card 00-034-0842 (Eggleton, 1977), which was found to have the best match with the Bulong nontronite XRD pattern. This PDF card was used as the main reference in this route, as the deficiency of nontronite reflections, captured by split pseudo-Voigt (SPV)-type peaks from WPPF of the nontronite pattern, made it difficult to use LSI indexing to assign a credible space group. The extent of preferred orientation of a set of patterns of the enriched Bulong nontronite mixed with varying amounts of $\mathrm{CaF}_{2}$ was assessed by comparing basal and non-basal reflection intensities. This set of standard mixtures was also used to calibrate the $Z M V$ factor later. The nearest randomly orientated nontronite pattern was assumed to be the one with the largest non-basal to basal reflection intensities ratio, i.e. $I_{d=4.5} / I_{d=15}$. LSI indexing of the captured reflections with weighting factors from the intensities of the nearest randomly orientated patterns was used to determine the lattice parameters with indexing that best agreed with PDF card 00-034-0842.

Another Pawley phase model was developed using the monoclinic C2/m space group (Besson et al., 1983; Tsipursky \& Drits, 1984). As demonstrated in the central route of Fig. 1, an LP search in the monoclinic crystal system was used to find the most suitable lattice parameters from the whole measured pattern. LP search is a Monte Carlo-based WPPD approach, avoiding the difficulties associated with extracting peak $d$ values from the complex nontronite patterns. Unit-cell dimensions with the lowest $R_{\text {wp }}$ (weighted pattern fit indicator) were chosen after multi-cycle refinements ( 150 cycles with refinement allowed to continue beyond the set convergence conditions).

The two routes described above define space groups and lattice parameters that are quite different. The nontronite $h k l$ reflection positions, their intensities and their associated errors were generated for these two space groups and sets of lattice parameters by Pawley WPPD. Note that the scale factor refinement and preferred orientation correction should not be used during Pawley WPPD, as the net intensities should be generated without any scale. Only reflections with intensity error lower than the intensity value were adopted and used in the Pawley phase model. This reduction in the number of reflections used was gradually achieved by several cycles of omitting reflections and re-fitting the new model.

The relative intensities of the reflections in the enriched nontronite pattern are often affected by sample preferred orientation. Therefore, the intensities of each reflection were corrected by the intensity ratio from the nearest randomly orientated nontronite pattern. This means that the $h k l$ reflections in the final nontronite Pawley phase model were built from two sources: the enriched nontronite pattern with more reflection details and the nearest randomly orientated nontronite pattern (spiked) with correct intensity ratio. The intensities were thereafter fixed for further model development.

User-defined convolutions were used to model asymmetric nontronite peaks after the above $h k l$ reflections were determined. The asymmetry and FWHM of the nontronite peaks are $h k l$ dependent (anisotropic); therefore, $\mathrm{SH}$ were employed to represent the asymmetric peak shape factor using 'circles' convolution to achieve better fitting (TOPAS Version 4.2 Technical Reference). Anisotropic crystal size and strain were also represented by another two SH in Lorentzian and Gaussian convolutions. These user-defined convolutions can also be employed in Pawley WPPD, providing appropriate starting values are assigned. Once determined, the SH coefficients of the asymmetric peak shapes can be fixed, leaving the SH coefficients for anisotropic size and strain refinable.

2.2.2. Building the peaks phase group model. A peaks phase group model was also developed to quantify nontronite, as indicated in the left-hand route in Fig. 1. This approach was modified from the method of Scarlett \& Madsen (2006), who successfully quantified corundum with a single peaks phase containing multiple reflections (characterized by peak position and reflection intensity). Confined to a uniform peak shape, a single peaks phase cannot be readily fitted to the complex nontronite pattern, especially the asymmetric peak shapes (Scarlett et al., 2008). To avoid this restriction, multiple peaks phases were used as a group in which each peaks phase fits one peak so that individual peak shape parameters can be assigned; however, the scale factors of these peaks phases were constrained to be a single refinable parameter so they could be scaled together. The SPV peak shape parameters of reflections at the same $2 \theta$ were also constrained when multiple nontronite patterns were fitted simultaneously. The positions and intensities of the peaks phase group were determined 
from WPPF using SPV profiles. An example of the TOPAS input file of the peaks phase group and for comparison an example file for a single peaks phase are illustrated in Fig. 2.
2.2.3. Calibrating the $Z M V$ factor. The procedure for $Z M$ factor calibration was essentially the same as that used by Scarlett \& Madsen (2006) except that the results of multiple

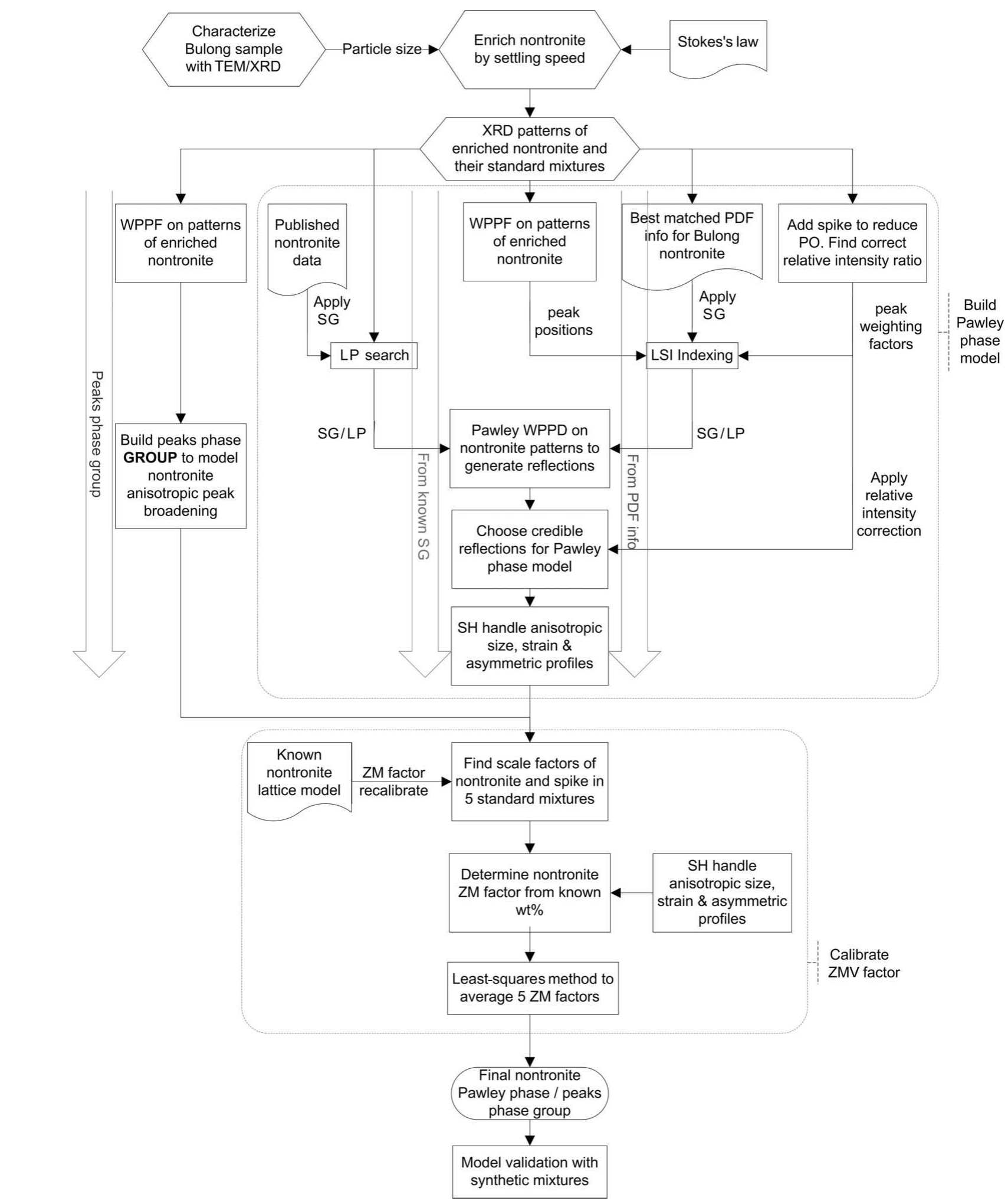

Figure 1

Flow chart for applying the modified PONKCS method to Bulong nontronite, outlining the two major stages: 'Build Pawley phase model' and 'Calibrate $Z M V$ factor'. The PONKCS process can start from the best matched PDF information, from a specified space group or from a known lattice model by recalibrating the $Z M$ factor. The peaks phase group route bypasses the difficulties associated with indexing a complex pattern. SG denotes space group and $\mathrm{PO}$ preferred orientation. 
standard mixtures were used and averaged. Rietveld errors reported in the TOPAS program only give an estimate of the precision of the refinement process. In order to take into account other possible errors, five patterns from standard mixtures with weight ratios of nontronite to $\mathrm{CaF}_{2}$ of $1: 9,3: 7$, 5:5, 7:3 and 9:1 were fitted simultaneously to extract scale factors for both phases. The lattice parameters of every nontronite pattern were linked, while the lattice parameters of the $\mathrm{CaF}_{2}$ spike were predefined and fixed. The same $\mathrm{SH}$ coefficients were used for asymmetric peak shape for each pattern, while the SH for anisotropic crystal size and strain were allowed to refine separately. According to quantitative Rietveld theory (Bish \& Howard, 1988; Hill \& Howard, 1987; O'Connor \& Raven, 1988), the $Z M$ factor of nontronite (non) was determined from the weight ratio, the refined scale factors and the $Z M V$ factor of the standard (Scarlett \& Madsen, 2006):

$$
Z M_{\text {non }}=\frac{W_{\text {non }}}{W_{\mathrm{CaF}_{2}}} \frac{S_{\mathrm{CaF}_{2}}}{S_{\text {non }}} \frac{Z M V_{\mathrm{CaF}_{2}}}{V_{\text {non }}}
$$

Here $Z M, V, S$ and $W$ refer to the $Z M$ factor (unit-cell mass), unit-cell volume, scale factor and weight percent of each phase described by the subscript, respectively.

The $Z M$ results generated from the five standard mixtures were slightly different. A least-squares method was adopted to

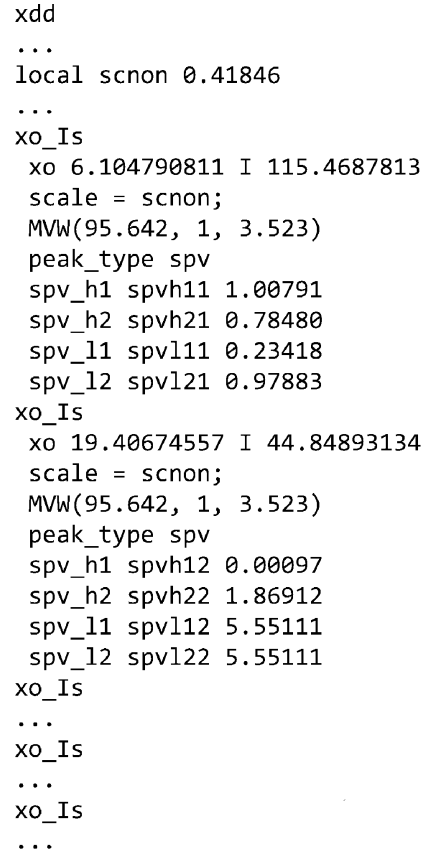

Table 2

ICP-OES results of the major element weight percentages in Bulong nontronite and the nontronite standards from the Clay Mineral Society (ignited at $1323 \mathrm{~K}$ ).

\begin{tabular}{|c|c|c|c|c|c|c|c|c|c|c|}
\hline & $\mathrm{iO}_{2}$ & $\mathrm{Al}_{2} \mathrm{O}$ & $\mathrm{Fe}_{2} \mathrm{C}$ & $\mathrm{MgO}$ & $\mathrm{CaO}$ & $\mathrm{Na}_{2} \mathrm{O}$ & $\mathrm{NiO} \mathrm{CoO}$ & $\mathrm{TiO}_{2}$ & $\mathrm{~K}_{2} \mathrm{O}$ & ) Tot \\
\hline long & 56.14 & & 25.50 & 3.50 & 0.33 & 1.04 & 2.520 .07 & - & - & 99.4 \\
\hline & 51.3 & & & 0. & 3. & 0.0 & - & 0.02 & & 99.5 \\
\hline $\mathrm{NAu}-2 \mid$ & 56.18 & 3.11 & 37.85 & 0.26 & 2.34 & 0.14 & - & 0.02 & 0.01 & 99.9 \\
\hline
\end{tabular}

$\dagger$ Data from Keeling et al. (2000).

effectively average the results by adjusting the final nontronite $Z M$ value to minimize the quadratic sum of the differences between calculated and weighed weight percent for the five standard mixtures. The uncertainty of the calibrated $Z M$ factor was calculated from the refined scale factors of individual standard mixtures plus or minus one Rietveld standard uncertainty.

The $Z M$ factor and corresponding reflection intensities were not scaled to match the real nontronite density because this does not affect quantification (Scarlett \& Madsen, 2006). The final nontronite Pawley phase model was similar to that described by Scarlett \& Madsen (2006) except that the anisotropic crystal size and strain were represented by $\mathrm{SH}$ in Lorentzian and Gaussian convolutions; the asymmetric peak shape was fitted by 'circles' convolutions in which SH were used as the convolution factor. A March model correction for preferred orientation was used for the five standard mixture patterns.

The $Z M V$ factor calibration for the peaks phase group was the same as described above. The calculated $Z M V$ factor was evenly allocated to each peaks phase, since the nontronite phase concentration was represented by the sum of the weight percent of all the peaks phases. As no lattice information is used in the peaks phase model, the unit-cell volume is not known; hence the $Z M$ factor cannot be separated from the $Z M V$ factor.

\section{Results and discussion}

The two lattice models and one peaks phase group model were compared by validation with the six independent mixtures of quartz, goethite and the enriched Bulong nontronite.

\subsection{Chemical analysis}

The elemental composition of Bulong nontronite determined by ICP-OES is shown in Table 2. Bulong nontronite is higher in $\mathrm{Mg}$ and $\mathrm{Ni}$ and lower in $\mathrm{Fe}$ and $\mathrm{Ca}$ than the two standard nontronite samples (NAu-1 and NAu-2) from Port Lincoln, Southern Australia (Keeling et al., 2000; Gates et al., 2002). The differences in the cation substitutions make the unit-cell mass, and therefore the $Z M V$ factor, different. A feature of the PONKCS method is that, if there is any amorphous content in the enriched unknown phase, it will be included with this phase. Evidence of amorphous content has

Figure 2

(a) An example of a peaks phase group in TOPAS input syntax, which fitted nontronite anisotropic broadened peaks independently, with the scale factor constrained to the same refinable value. 'xo' stands for the peak position $\left({ }^{\circ} 2 \theta\right)$; 'I' stands for reflection intensity. The full width at half-maximum on the left (spv_h1) and right sides (spv_h2) and the Lorentzian fractions on the left (spv_l1) and right sides (spv_12) were constrained when multiple patterns were fitted simultaneously. (b) A single peaks phase model, similar to that introduced by Scarlett \& Madsen (2006), which is restricted to a uniform peak profile. 
been confirmed by transmission electron microscopy (see supplementary material ${ }^{\mathbf{1}}$ ). The more amorphous material there is, the higher the calibrated $Z M$ factor will be as the total mass of both the amorphous content and the target unknown phase are both divided by the smaller scale factor of the lower peak intensity of the unknown phase.

\section{2. $\mathbf{S H}$-assisted convolutions in the lattice model}

The merits of using SH-assisted convolutions in the Pawley phase model are shown in Fig. 3. The difference plots and the goodness of fit (GOF) suggest that the anisotropic peak broadening and asymmetric peaks of the nontronite pattern were successfully fitted by $\mathrm{SH}$-assisted convolutions. These convolutions also enabled the Pawley phase model to fit better during Pawley WPPD. As with the structure refinement strategy described by McCusker et al. (1999), it is critical to follow the refinement strategy for SH illustrated in Fig. 4, otherwise too many parameters, without correct start values, can lead to divergence. For the same reason, only secondorder $\mathrm{SH}$ were used for each convolution. The quantitative results of the original and modified Pawley phase models in both space groups are compared in Figs. 5 and 6. It is clear that the $\mathrm{SH}$-assisted convolutions and proper refinement strategy improved the fitting and accuracy of the analysis. The QPA results from the two Pawley phase models based on the two space groups were similar, suggesting that phase abundance is independent of crystallographic properties as long as the fitting is good.

It should be noted that the asymmetric peak of smectite due to turbostratic disorder has been successfully fitted by a supercell approach (Ufer et al., 2004) using the Rietveld analysis program BGMN (Bergmann \& Kleeberg, 1998). It was later demonstrated that this supercell model was capable of accurately quantifying high smectite content (about $70 \mathrm{wt} \%$ ) bentonite samples (Ufer et al., 2008). This supercell approach is universally applicable to any Rietveld platform and has been used in the program MAUD (Lutterotti et al., 1999) to facilitate quantitative texture analysis of montmorillonite and opal in uniaxially pressed samples (Lutterotti et al., 2009; Chateigner et al., 2010). In the present study the supercell structure from $B G M N$ syntax (http://www.bgmn.de/ download-structures.html) was translated into TOPAS syntax (see supplementary material) and achieved good fitting for the Bulong nontronite pattern, as shown in Fig. 7. The quantitative result for nontronite using the supercell model was not sensitive to cation occupancy in the tetrahedral-octahedraltetrahedral layer, as Ufer et al. (2008) described, but varied with the absolute number of interlayer cations in the supercell model. This suggests that accurate sample chemistry and structure should be known before applying the supercell model for quantification. However, to date, the supercell model has been the only structural model describing asymmetric peaks that arise from turbostratic disorder.

\footnotetext{
${ }^{1}$ Supplementary material discussed in this paper is available from the IUCr electronic archives (Reference: CG5190). Services for accessing this material are described at the back of the journal.
}

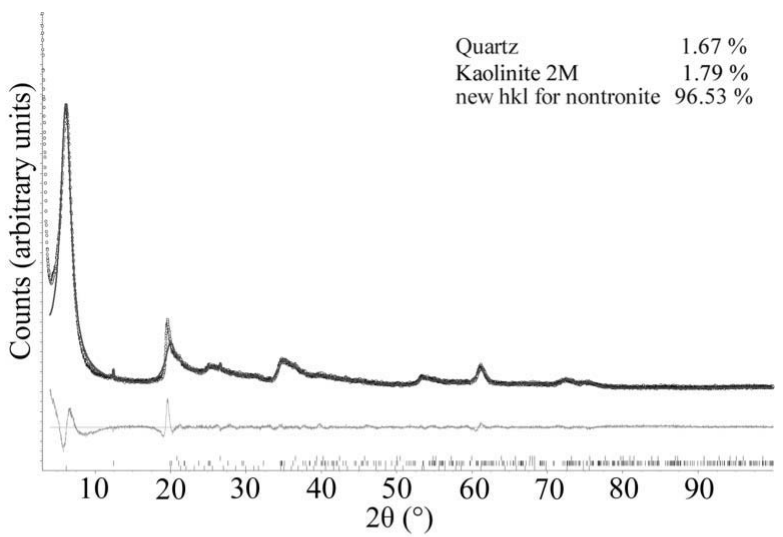

(a)

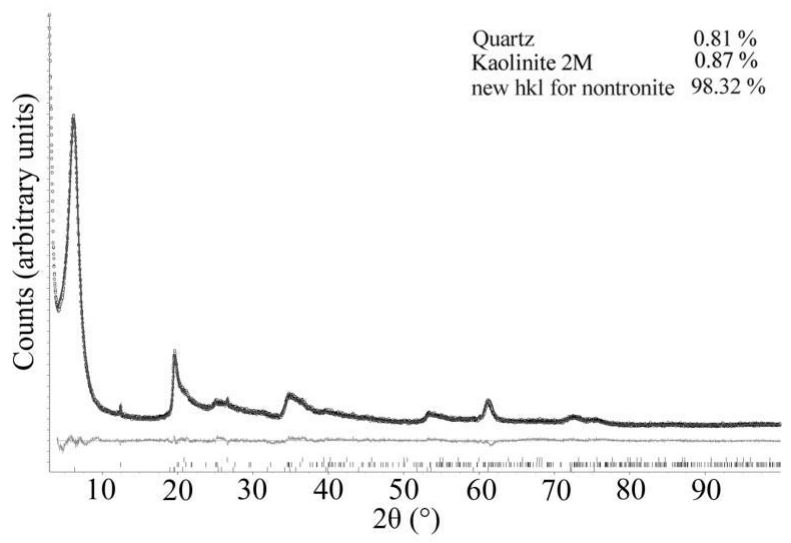

(b)

Figure 3

Comparison of the whole pattern fitting using (a) the normal nontronite Pawley phase model with isotropic crystal size and March preferred orientation model (Dollase, 1986), GOF 3.12, and (b) the SH-assisted nontronite Pawley phase model with anisotropic crystal size, strain and peak shape convolution, GOF 1.51. The circles represent measured data and the continuous line indicates the calculated pattern. A small amount of quartz and kaolinite residue appeared in the enriched nontronite pattern. Both fits started from $3.98^{\circ} 2 \theta$ to avoid background at low angles due to air scattering.

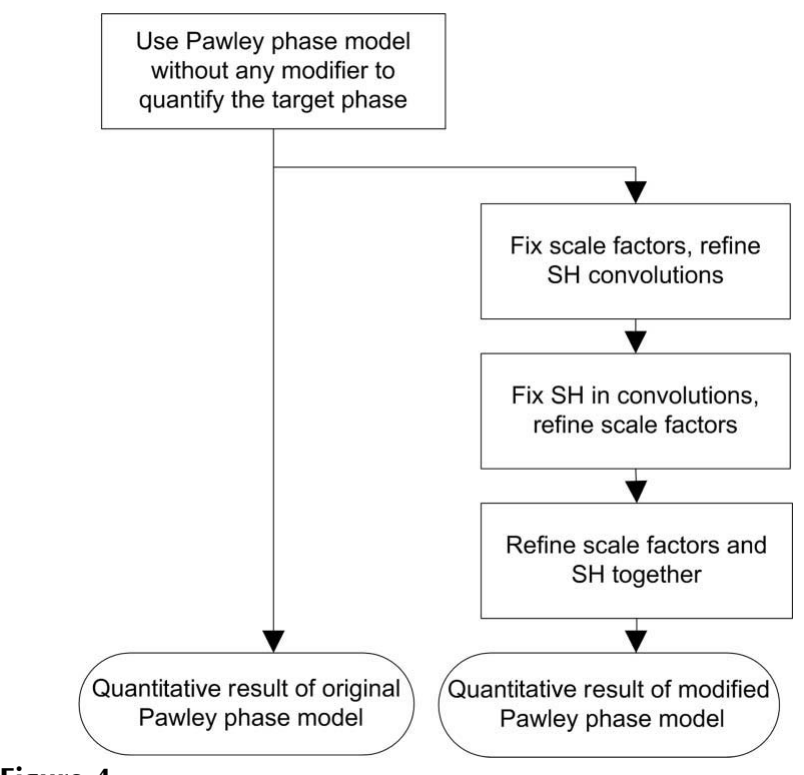

Figure 4

Refinement strategy applied when using $\mathrm{SH}$ as convolution factors. 


\subsection{Nontronite quantification by peaks phase group model}

Similar to other QPA approaches, such as the multiple-line reference-intensity-ratio method or the mean-normalizedintensity method ( $\mathrm{Li}$ et al., 1994), the peaks phase model is independent of crystallographic properties and only considers peak fitting. However, the nontronite pattern contains various peak shapes, including a major sharp peak at low angle, asymmetric peaks due to turbostratic disorder and broad humps. As shown in Fig. 8, a single peaks phase cannot fit this complex pattern as it is restricted by the uniform peak shape, although it is normally excellent for materials with isotropic peak shape, such as corundum (Scarlett \& Madsen, 2006). A multiple peaks phase model has to be used to fit the complex nontronite pattern, which contains anisotropic peak broadening. The comparison of quantification results using a single peaks phase and a peaks phase group is shown in Fig. 9, once again demonstrating the benefit to accurate quantitative analysis obtained from better fitting of the nontronite pattern.

\subsection{Quantification results of all models}

According to the $Z M$ calibration procedures described in $\S 2.2 .3$, the calibrated $Z M$ factor for the nontronite Pawley phase based on space group $C 2 / m$ is 0.99 (1); the $Z M$ factor for the Pawley phase based on space group $P 3$ is 1.46 (3). These calibrated $Z M$ factors are directly proportional to the intensities assigned to each reflection in the Pawley phase. The final

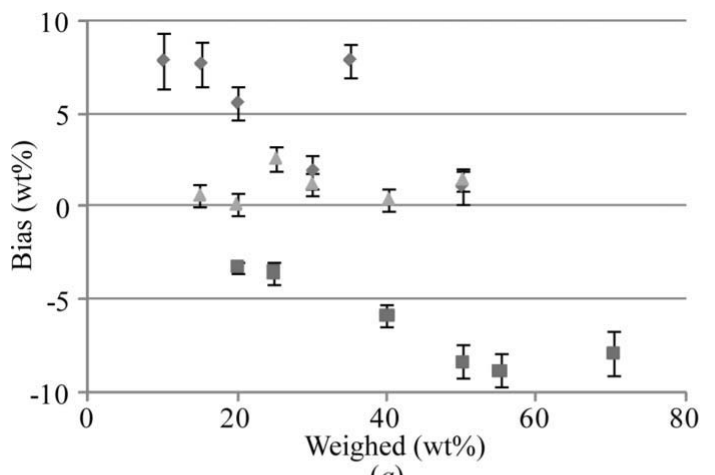

- nontronite goethite $\triangle$ quartz

(a)

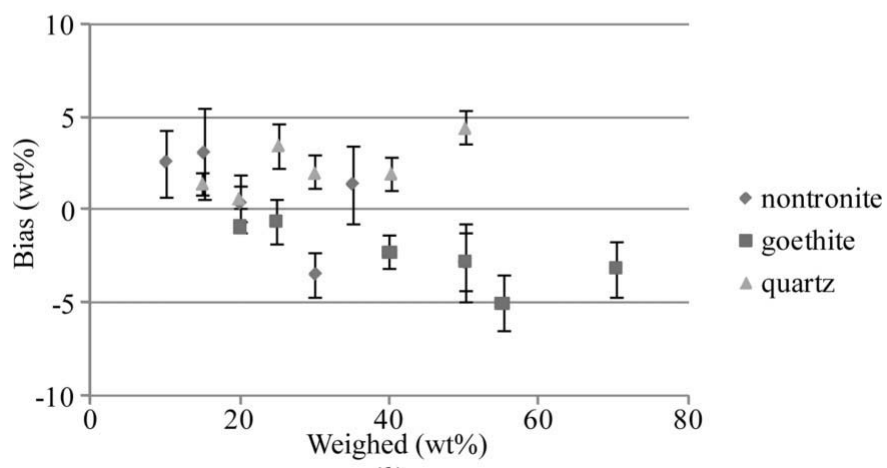

(b)

Figure 5

PONKCS quantification results of synthetic mixtures using the $P 3$ space group Pawley phase model without $(a)$ and with (b) $\mathrm{SH}$-assisted convolutions. The deviation of results with SH-assisted convolution is smaller than those without. Error bars represent a $6 \sigma$ range of quantification results. quantitative results for the six synthetic mixtures of quartz, goethite and nontronite using the two new Pawley phase models and the peaks phase group model are shown in Table 1, and Figs. 5(b), 6(b) and 7(b). TOPAS does not consider the uncertainty of the $Z M$ factor of the Pawley phase during refinement; therefore the uncertainties of the calibrated $Z M$ factors were propagated to the final quantification results manually according to the Rietveld quantification relationship

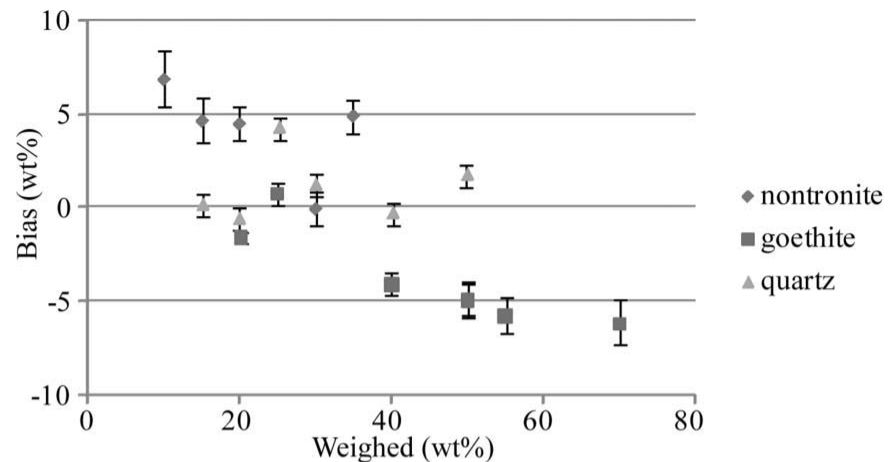

(a)

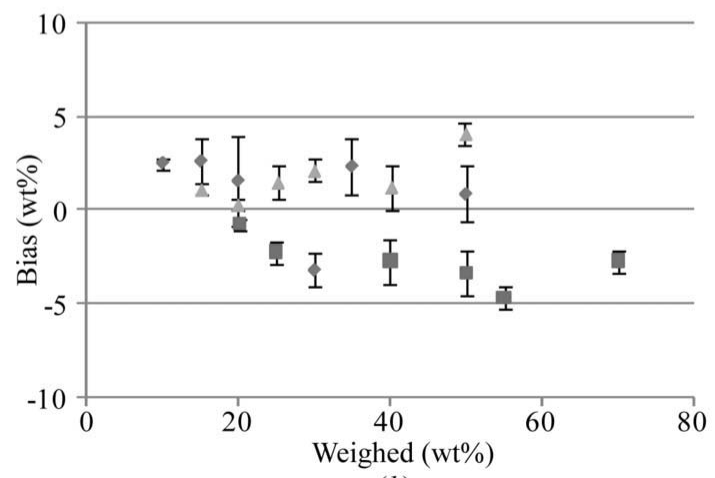

- nontronite - goethite $\Delta$ quartz

Figure 6

(b)

PONKCS quantification results of synthetic mixtures using the $C 2 / \mathrm{m}$ space group Pawley phase model without $(a)$ and with $(b)$ SH-assisted convolutions. The deviation of results with $\mathrm{SH}$-assisted convolution is smaller than those without. Error bars represent a $6 \sigma$ range of quantification results.

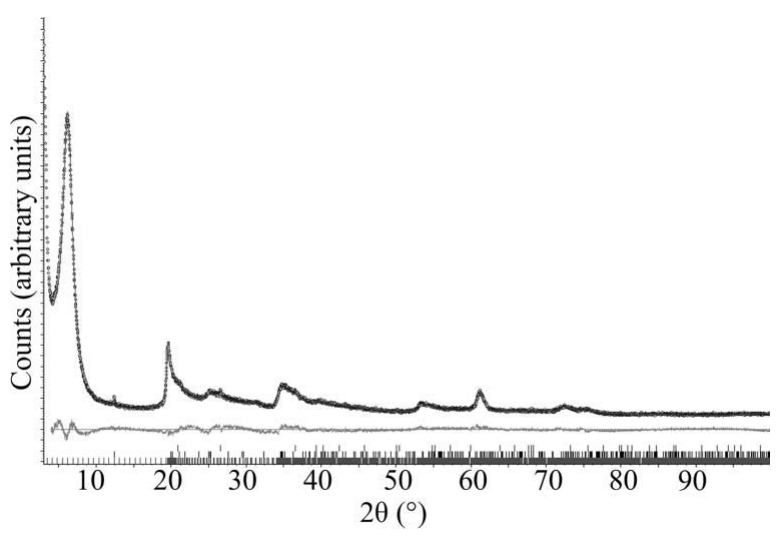

Figure 7

A demonstration of the excellent fitting achieved using the supercell structure model (Ufer et al., 2004) in the TOPAS software. Trace amounts of quartz and kaolinite residue are present in the enriched nontronite pattern. The bottom row of markers correspond to the nontronite supercell model. 
of the phase scale and phase $Z M$ factors. The final uncertainties of the phase concentrations are shown by the figures in brackets in Table 1.

The results of the peaks phase group model were inferior to those of the Pawley phase model, because the peaks phase group model or single peaks phase model intrinsically do not allow for preferred orientation correction once the peak intensities are defined and fixed, whereas for both Pawley phase models the preferred orientation effect was corrected during refinement. This also explains why the nontronite quantitative results using a peaks phase group in Fig. 7(b) showed a trend of increasing underestimation, as the extent of the preferred orientation increased with nontronite content. Additionally, as goethite is a heavy absorber and quartz is a light absorber when using $\mathrm{Cu} K \alpha$ radiation, microabsorption effects are expected to lead to overestimation of quartz content and underestimation of goethite content.

Ideally, purified nontronite from an unknown sample should be obtained to develop either lattice or peaks phase group models. However, examination of the XRD patterns of nontronite samples obtained from other major nickel laterite projects in Western Australia suggest that the diffraction

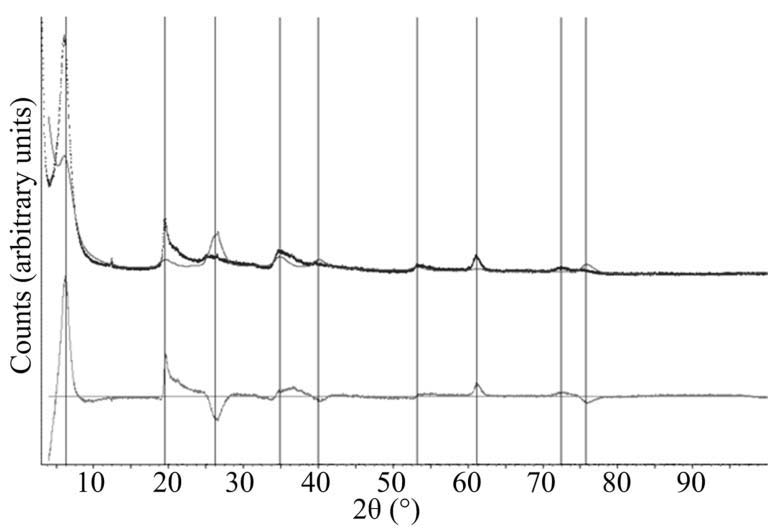

(a)

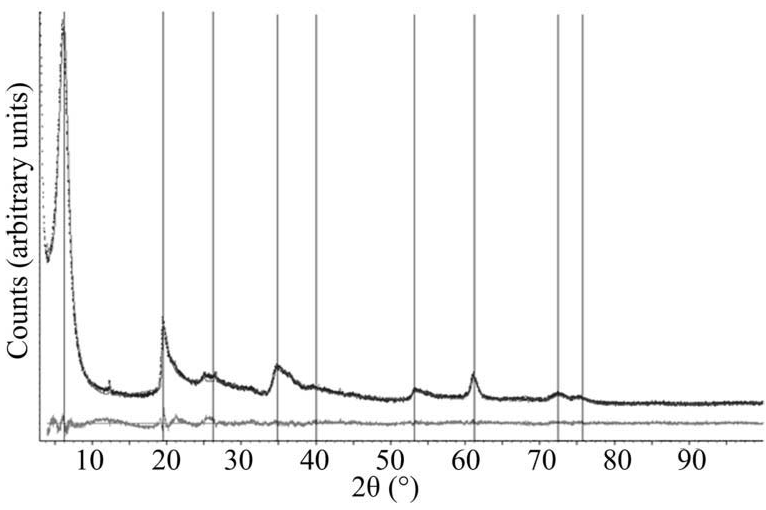

(b)

Figure 8

(a) A single peaks phase with uniform peak shape cannot fit the complex nontronite pattern. (b) A peaks phase group with individual peak shape factors improved the fit to the nontronite pattern. Both models use the same set of peak positions and intensities. The dots represent the measured pattern and the continuous line indicates the calculated pattern. Both fits started from $3.98^{\circ} 2 \theta$ to avoid the background at low angles due to air scattering. patterns do not differ greatly. The XRD pattern in this paper is similar to that of NAu-1 (Keeling et al., 2000). Taylor \& Matulis (1994) using SIROQUANT software (Taylor, 1991) showed that a montmorillonite $(h k l)$ file could be used to quantify montmorillonite samples from other locations. Nevertheless, building individual lattice models and calibrating $Z M$ factors for target phases are always encouraged, because of the variation of cation substitutions, interlayer exchangeable cations and potential amorphous content in actual samples.

Another use of the PONKCS method for unknown phases with complex patterns, called 'envelope fitting', uses an unlimited number of reflections generated from Pawley fitting to fit asymmetric peaks (Kern, 2011). However, as this method still uses isotropic peak shapes, it does not give good fitting without peak shape modifiers (Vanhoyland, 2009). 'Envelope fitting' may cause problems if the lattice parameters are refined in the Rietveld analysis because the well defined and fixed reflection family in 'envelope fitting' may not come from the same zone axis, so if the lattice parameters change these peaks may shift and deform the overall 'envelope' shape. In extreme cases, reflections with fixed intensity may shift to an adjacent 'trough', resulting in fitting errors. We have demonstrated that a smaller number of reflections, selected to minimize this risk, and anisotropic peak shape modifiers, such as $\mathrm{SH}$-assisted convolutions, are capable of handling multiple peak shapes and accurately quantifying nontronite even at low concentration in multiple phase mixtures.
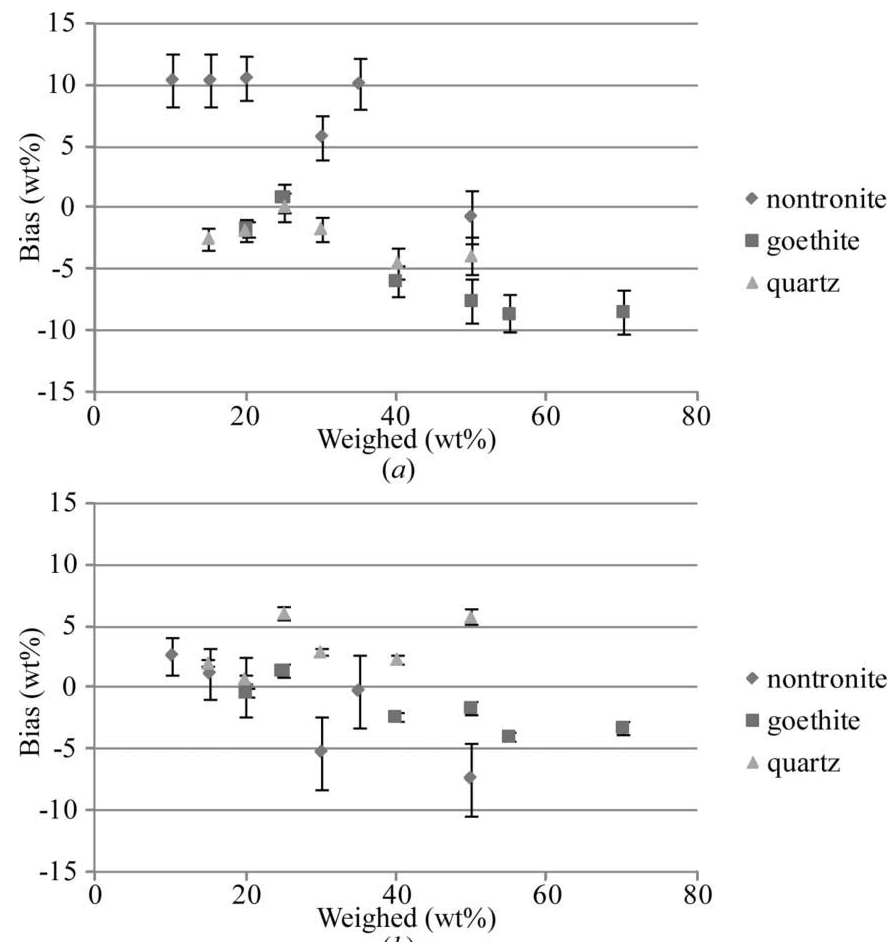

(b)

Figure 9

PONKCS quantification results of synthetic mixtures using $(a)$ a single peaks phase and $(b)$ a peaks phase group. The deviation of results using the peaks phase group is smaller than that using a single peaks phase. Error bars represent a $6 \sigma$ range of quantification results. 


\section{Conclusion}

Two modified models were developed for the PONKCS method and were used to successfully quantify Bulong nontronite in a laterite ore. This partially known crystal structure was represented by two Pawley phase lattice models, with spherical harmonics (SH)-assisted convolutions, and a peaks phase group model.

(a) According to the availability of crystallographic information of the phase in question, the PONKCS process as illustrated in Fig. 1 can start from the best matched PDF information, from a known space group or from a known lattice model by recalibrating the $Z M$ factor.

(b) The use of spherical harmonics as peak shape convolution factors in the Pawley phase model successfully reproduced asymmetric peaks of the complex nontronite pattern both in Pawley whole powder pattern decomposition and in Rietveld quantification after $h k l$ reflections were defined for the Pawley phase model. A refinement strategy should be applied to avoid parameter divergence when using $\mathrm{SH}$ assisted convolutions in the Pawley phase model.

(c) The quantification result of an unknown phase using a Pawley phase model is essentially independent of the crystallographic properties (space group, reflection indices) assigned as long as a good fit is achieved.

(d) A peaks phase group can be used to fit a pattern containing anisotropically broadened reflections. This approach bypasses the difficulties associated with indexing complex patterns in the Pawley phase route but suffers from an inability to correct for preferred orientation effects.

(e) All Pawley phase models and peaks phase group models produced acceptable accuracy and consistency with the quantification results of simulated nickel laterite samples and can be generally applied to quantitative phase analyses of nontronite in laterites. The modified models should be applicable to quantitative phase analyses of other partial or no known crystal structure phases with complex XRD patterns.

The PhD scholarship of Xiaodong Wang is funded by the Endeavour Postgraduate Award from the Department of Education, Employment and Workplace Relations, Australian Government. The authors acknowledge the financial support of the Parker Cooperative Research Centre. Ross P. Williams is thanked for his constructive suggestions.

\section{References}

Bayliss, P. (1989). Powder Diffr. 4, 19-20.

Bergmann, J. \& Kleeberg, R. (1998). Mater. Sci. Forum, 278-281, 300305.
Besson, G., Bookin, A. S., Dainyak, L. G., Rautureau, M., Tsipursky, S. I., Tchoubar, C. \& Drits, V. A. (1983). J. Appl. Cryst. 16, 374-383. Bish, D. L. \& Howard, S. A. (1988). J. Appl. Cryst. 21, 86-91.

Chateigner, D., Blanchart, P., Deniel, S., Lutterotti, L. \& Wenk, H.-R. (2010). Adv. Sci. Technol. 68, 13-22.

Cheary, R. W. \& Coelho, A. (1992). J. Appl. Cryst. 25, 109-121.

Dekov, V. M., Kamenov, G. D., Stummeyer, J., Thiry, M., Savelli, C., Shanks, W. C., Fortin, D., Kuzmann, E. \& Vértes, A. (2007). Chem. Geol. 245, 103-119.

Dollase, W. A. (1986). J. Appl. Cryst. 19, 267-272.

Eggleton, R. A. (1977). Clay Miner. 12, 181-194.

Elias, M., Donaldson, M. J. \& Giorgetta, N. E. (1981). Econ. Geol. 76, 1775-1783.

Elliot, A., Fletcher, H., Li, J., Watling, H. \& Robinson, D. J. (2009). 39th Annual Hydrometallurgy Meeting and 48th Annual Conference of Metallurgists of CIM, pp. 537-549. Montreal: Canadian Institute of Mining, Metallurgy and Petroleum.

Gates, W. P., Slade, P. G., Manceau, A. \& Lanson, B. (2002). Clays Clay Miner. 50, 223-239.

Gaudin, A., Decarreau, A., Noack, Y. \& Grauby, O. (2005). Austr. J. Earth Sci. 52, 231-241.

Hill, R. J. \& Howard, C. J. (1987). J. Appl. Cryst. 20, 467-474.

Järvinen, M. (1993). J. Appl. Cryst. 26, 525-531.

Keeling, J. L., Raven, M. D. \& Gates, W. P. (2000). Clays Clay Miner. 48, 537-548.

Kern, A. (2011). 7th TOPAS Bruker Users' Meeting, 5-6 February 2011, Sydney, Australia.

Landers, M., Gilkes, R. J. \& Wells, M. A. (2009). Clays Clay Miner. 57, 751-770.

Li, D. Y., O'Connor, B. H., Chen, Q. T. \& Zadnik, M. G. (1994). J. Am. Ceram. Soc. 77, 2195-2198.

Lutterotti, L., Matthies, S. \& Wenk, H.-R. (1999). IUCr Commission on Powder Diffraction Newsletter, No. 21, pp. 14-15.

Lutterotti, L., Voltolini, M., Wenk, H. R., Bandyopadhyay, K. \& Vanorio, T. (2009). Am. Mineral. 95, 98-103.

McCusker, L. B., Von Dreele, R. B., Cox, D. E., Louër, D. \& Scardi, P. (1999). J. Appl. Cryst. 32, 36-50.

McDonald, R. G. \& Whittington, B. I. (2008). Hydrometallurgy, 91, $35-55$.

Moore, D. M. \& Reynolds, R. C. (1997). X-ray Diffraction and the Identification and Analysis of Clay Minerals, 2nd ed. Oxford University Press.

O'Connor, B. H. \& Raven, M. D. (1988). Powder Diffr. 3, 2-6.

Scarlett, N. V. Y. \& Madsen, I. C. (2006). Powder Diffr. 21, 278-284.

Scarlett, N. V. Y., Madsen, I. C. \& Whittington, B. I. (2008). J. Appl. Cryst. 41, 572-583.

Singh, B. \& Gilkes, R. J. (1992). Eur. J. Soil Sci. 43, 77-98.

Taylor, A. (2007). ALTA Ni/Co 2007 - 12th Nickel/Cobalt Conference, p. 46. Melbourne: ALTA Metallurgical Services.

Taylor, J. C. (1991). Powder Diffr. 6, $2-9$.

Taylor, J. C. \& Matulis, C. E. (1994). Powder Diffr. 9, 119-123.

Tsipursky, S. I. \& Drits, V. A. (1984). Clay Miner. 19, 177-193.

Ufer, K., Roth, G., Kleeberg, R., Stanjek, H., Dohrmann, R. \& Bergmann, J. (2004). Z. Kristallogr. 219, 519-527.

Ufer, K., Stanjek, H., Roth, G., Dohrmann, R., Kleeberg, R. \& Kaufhold, S. (2008). Clays Clay Miner. 56, 272-282.

Vanhoyland, G. (2009). The 8th Pharmaceutical Powder X-ray Diffraction Symposium, 4-7 May 2009, Glasgow, Scotland.

Whittington, B., Johnson, J. A., Quan, L. P., McDonald, R. G. \& Muir, D. M. (2003). Hydrometallurgy, 70, 47-62. 